\title{
A comparison of two low grade heat recovery options
}

\author{
Conor Walsh ${ }^{a^{*}}$, Patricia Thornley ${ }^{\text {a }}$ \\ a Tyndall Centre for Climate Change Research, Pariser Building, \\ The University of Manchester, Manchester, M13 9PL, UK \\ * Corresponding author. Email: Conor.Walsh@manchester.ac.uk; \\ Tel. +44(0) 1612754332
}

\begin{abstract}
Low grade heat (LGH) recovery is one way of increasing industrial energy efficiency and reducing associated greenhouse gas emissions. The organic rankine cycle (ORC) and condensing boilers are two options that can be used to recover low grade heat $\left(<250{ }^{\circ} \mathrm{C}\right)$. This paper assesses the lifecycle greenhouse gas reduction impacts and discounted payback periods associated with both technologies. Generation of electricity through the operation of the ORC saves approximately $11 \mathrm{kt}$ of $\mathrm{CO}_{2}$ annually, but the high carbon intensity of the coking process means this has a negligible influence $(<1$ $\%)$ on the overall process lifecycle impacts. However, if the electricity generated offsets the external purchasing of electricity this results in favourable economic payback periods of between 3 and 6 years. The operation of a condensing boiler within a woodchip boiler reduces the fuel required to achieve an increased thermal output. The thermal efficiency gains reduce the lifecycle impacts by between 11 and $21 \%$., and reflect payback periods as low as 1.5 to 2 years, depending on the condenser type and wood supply chain. The two case studies are used to highlight the difficulty in identifying LGH recovery solutions that satisfy multiple environmental, economic and wider objectives.
\end{abstract}

Keywords: Low grade heat; lifecycle assessment; discounted payback

\section{$1 \quad$ Introduction}

The recovery of low grade heat (LGH) has been recognised as a potential means of improving the energy efficiency of industrial installations. Most industrial installations emit large quantities of LGH as part of normal operations. Traditionally increasing energy consumption was seen as being preferable to recovered heat of lower thermal quality. In most instances, the feasibility of LGH recovery will depend on the thermal quality of the heat as well as its potential uses. Ideally, recovered heat will have the capacity to be used within the installation itself. Alternatively, "over the fence" options will have to be evaluated. In order to be appropriate for integration into existing industrial processes, LGH recovery options must meet a number of the requirements. Process managers will need reassurances on any new technology, particular if the process is well established. The need to balance the perceived risk and potential rewards is a barrier to the uptake of new technologies. Primarily the technology must be suitable for the low temperature range involved. The integration of any new technology must be unobtrusive in terms of normal process operation. Any potential technology must be sufficiently flexible to reflect the potential variability within the process, particularly where the process runs continuously. Once these requirements are met it is vital that there is a use for the recovered heat, either within or outside the process. Finally any technology must demonstrate sufficient redundancy to allow it to be repaired or removed without issue. This paper seeks to inform the expectations of what benefits can be reasonably expected by the recovery of LGH by assessing its potential for reducing the lifecycle environmental impact associated with two different industrial processes as well as the likely discounted payback period (DPP).

\subsection{Industrial case-studies.}

Two alternative technologies have been identified as being suitable for the recovery LGH; the organic rankine cycle (ORC) and condensing boiler. These have been selected as they are sufficiently different to allow for interesting comparison of the any benefits while demonstrating established technologies. The first case study identified is the integration of an ORC to recover heat from the flue gas leaving a coke oven within an integrated steel works. The Rankine cycle is a thermodynamic 
cycle which converts heat into work which ultimately generates electricity through a turbine. It is likely that approximately $80 \%$ of the electricity generated globally is a result of the Rankine cycle. Within a Rankine cycle heat is supplied externally to a closed loop, which usually uses water as the working fluid. Figure 1 below demonstrates a simplified Rankine cycle.

\section{Figure 1 about here}

A Rankine cycle which employs water as a working fluid is not economical if recovering heat below $370^{\circ} \mathrm{C}$. For that reason organic chemicals or refrigerants are often substituted for water within a Rankine cycle, resulting in what has been termed the Organic Rankine Cycle (ORC). Most organic fluids demonstrate relatively low critical pressures which require ORCs to be operated at lower pressures and with significantly smaller heat capacities than traditional water-vapour cycles. In an analogous point to the one discussed above, Lakew and Boland [2] state that if a process seeks to recover power from condensing vapour then it will be necessary to choose a working fluid with a critical temperature above that of the source fluid. Therefore, an ORC system must function below the temperature and pressure at which the fluids are chemically unstable [3]. McKenna and Norman [4] have identified the iron and steel sector as the largest user of heat with a heat load of approximately $213 \mathrm{PJ}$ but also demonstrate significant potential for heat recovery. While a number of streams containing LGH have been identified within the steel plant but flue gas from coke oven was chosen as being most suitable for recovery. The coking process itself is integral to modern integrated steel works, as coking coal is the main reducing agent in the blast furnace. Its suitability is due to the consistent operation of the coke oven and the high thermal quality compared to other sources of LGH as well as the reduced potential for process disruption. The gas stream has a temperature of $221{ }^{\circ} \mathrm{C}$ with a flow rate of $66 \mathrm{~kg} / \mathrm{s}$. This was estimated to yield $21 \mathrm{MW}$ of recoverable energy [5].

One of the most common means of improving thermal efficiency is the introduction of a condensing boiler to recover latent heat from the waste gas steam. Condensing boilers normally fall into two main categories, direct and indirect content systems. Within direct-contact condensing boilers there are no boundaries isolating hot combustion gases from the stream to be heated. An indirect contact condensing boiler recovers heat from hot flue gases by passing them through one or more heat exchangers. This benefit is more pronounced for raw biomass systems, where the higher moisture content means that up to half of the calorific value of the fuel is recoverable. Both for this reason and its lack of process disruption, Chen et al [6] have examined the impact of a condensing boiler on a Finnish woodchip fluidized bed boiler which provides heat for a district heating system. The woodchip plant demonstrates a basic (pre-condenser) output of $40 \mathrm{MW}$. The heating systems served by this plant generally consist of water radiators whereby the return water temperature is between 35 and $40^{\circ} \mathrm{C}$. The return water temperature is preheated in the condenser using both the recovered latent heat of water vapour and the sensible heat of the flue gas. It is estimated that the condenser increases the thermal output to $52 \mathrm{MW}$.

\section{$2 \quad$ Material and methods}

\subsection{Direct carbon savings}

The direct carbon saving for both systems are calculated in a different manner. It is estimated that 1 tonne of coke requires $2.95 \mathrm{GJ}$ to produce it. It is estimated that $2 \%$ of the energy demand is satisfied by electricity, $5 \%$ is satisfied by steam and $93 \%$ by a gas source [4]. This latter may include natural gas, blast furnace gas or coke oven gas (COG) itself. The calculation of the emissions associated with the production of coke was based on equation 4.2 published in [7] and shown below. The equation used in the calculation is shown below:

$$
t \mathrm{CO}_{2} / t \text { Coke }=\left[(1 / y) \times C_{\text {coal }}+\sum\left(Q_{\text {gasi }} \times E F_{\text {gasi }}\right)-\left(1 \times C_{\text {coke }}\right)\right] \times 44 / 12
$$


Within the equation y refers to the coke yield ( $\mathrm{t}$ coke/t coal), $\mathrm{C}_{\text {coal }}$ is the carbon content of coal (\% $\mathrm{w} / \mathrm{w}) . \mathrm{Q}_{\text {gas }}$ equates to the quantity of gas used in coke production $(\mathrm{Gj}) . \mathrm{EF}_{\text {gas }}$ represents the emission factor for each specific gas (t C/Mj). $\mathrm{C}_{\text {coke }}$ refers to the carbon content of coal (\% w/w). 44/12 is used to translate $\mathrm{C}$ into $\mathrm{CO}_{2}$. At the steelworks under review, the underfiring gas used in the production of coke was a mixture of blast furnace gas and COG. Based on the gas stream data provided by the environment department of Corus, it was assumed that blast furnace gas and coke oven gas (COG) represented 50/50 \% by volume (A. Patsos, Pers. Comm.). As the COG represents an energy source provided by the oven itself, its emissions are excluded from Equation 1 in order to prevent double counting. The carbon savings are estimated by comparing the emissions negated though the generation of electricity by the ORC.

The amount of carbon directly emitted is calculated based on the fuel demands and the carbon content of the woodchips themselves. The direct carbon savings due to the operation of the condensing boiler within a woodchip boiler are quantified based on the relative fuel savings per unit of thermal output. In order to accurately calculate fuel savings, an estimate for the thermal efficiency of the system without the condenser is necessary. Table 1 and Figure 2 below are taken from [6] and demonstrates the enthalpies of the various boiler process streams. Flow rates and enthalpy changes are used to calculate the boiler, condenser and combined thermal output, which in turn allow the thermal efficiency (w/o condenser) to be estimated.

\section{Table 1 about here}

\section{Figure 2 about here}

Based on the change in enthalpy between the hot and return water stream, the thermal output is confirmed at $52 \mathrm{MW}$. The change in enthalpies between the hot water and preheated water streams is used to estimate the output of the boiler itself. Relative fuel savings (not to be confused with fuel efficiency) per thermal output are estimated using equation 2.

$\%$ fuel Savings $=1-(\%$ efficiency without condenser $/ \%$ efficiency with condenser $)$

In order to gauge any additional and indirect benefits of LGH recovery, two alternative case studies (representing offsite and terminal woodchip production) are assessed from a lifecycle and technoeconomic perspective.

\subsection{Lifecycle assessment}

Lifecycle assessment (LCA) attempts to collate and characterise the environmental impacts (including climate change as well as wider impact categories) associated with the production, use and disposal of a product or service. Within LCA all associated impacts are expressed in terms of a rational reference, termed a functional unit. In order to communicate the lifecycle impact of LGH recovery, the reference unit is expressed in terms of process output. In this case, $1 \mathrm{~kg}$ of coking coal and $1 \mathrm{MWh}$ of heat are used as the functional units to which energy and resource requirements as well as emissions are allocated. In order to reflect the impact of both technologies two lifecycle modules are generated for each case study, reflecting conditions with or without LGH recovery technology. This is vital as any potential LGH technology will also represent additional material and energy requirements.

The lifecycle impacts are modelled using a proprietary software package [8]. Using this method the on-site emissions are estimated for both processes whereas upstream impacts are estimated based on data provided from literature. For example, the lifecycle impacts associated with coke production will include the emissions and resource consumption associated with the production and overseas transportation of coal for the coking process. By contrast the lifecycle impacts associated with heat from a woodchip boiler will include the emissions and resources embodied in the cultivation and harvesting of wood residue. Data from a number of sources were used to generate lifecycle modules 
for both systems. Because of the amount and diversity of the data necessary to populate a LCA it is unfeasible to present the data here.

\section{$2.3 \quad$ Techno-economic analysis}

It is likely that any attempt to reduce the environmental impact of industrial processes will need to demonstrate a degree of financial viability. Net Present Value (NPV), represents the difference between the sum of the discounted cash flows which are expected from the investment and the amount which is initially invested (equation 3).

$$
N P V=-C_{0}+\sum_{n=1}^{N} \frac{F_{n}}{(1+k)^{n}}
$$

The discounted payback period (DPP) reflects the period in which the cost of investment (and operation) is recouped. Whereby $n$ is the time period (year), $\mathrm{F}_{\mathrm{n}}$ the net cash flow for year $\mathrm{n}, \mathrm{C}_{0}$ is the initial investment, $\mathrm{k}$ the discount interest rate, assumed to be $5 \%$ and $\mathrm{N}$ is the number of years of the investment's lifetime or until the invest breaks even. In relation to the ORC it is assumed that while the external purchasing of electricity is negated the ORC will incur costs due to installation and maintenance. The Department of Energy and Climate Change estimate that extra large manufacturing industries paid on average 5.078p (ex vat) per $\mathrm{kWh}$ in 2009. The Climate Change Levy (CCL) for electricity was also estimated at $0.47 \mathrm{p} / \mathrm{kWh}$ [15]. For the condensing boiler the savings due to a reduced woodchip demand is compared against the increased electricity costs associated with additional fan operation as well as capital and installation costs. The DPP for the installation in question has already been calculated in [6] whereby relative fuel savings result in a revenue. In order to provide an alternative, the estimates for fuel savings were augmented to reflect terminal (onsite) chipping. It is estimated in [16] that the cost at the power plant for material transported $80 \mathrm{~km}$ (average for Finland) is approximately $€ 30-35 / \mathrm{solid}^{3}$. The cost of chipping at the terminal is taken from the same source and is estimated at $€ 1.8 /$ solid $\mathrm{m}^{3}$. Based on estimates of wood density and average annual exchange rates these estimates result in an increased value of $\$ 69 /$ tonne, an increase of $\$ 9 /$ tonne from the value used in Chen et al. [6]. This changes the impact of wood chip savings and results in a different range of NPV and DPP.

\section{$3 \quad$ Results}

\subsection{Direct carbon savings}

The Aspen Hysys ${ }^{\circledR}$ simulation program was used by the Centre for Process Integration (CPI) at the University of Manchester to estimate the net energy efficiency of an ORC system used to recover heat from an equivalent waste stream. In this analysis, it was assumed that Benzene was the working fluid with a flow rate of $400 \mathrm{~kg} / \mathrm{mol} / \mathrm{h}$ (A. Kapil, Pers. Comm.). The ORC energy efficiency was calculated at $11 \%$ based on the values shown in Table 2 .

\section{Table 2 about here}

The energy efficiency was estimated by subtracting the energy consumed by the pump from the energy generated by the turbine and dividing by the energy supplied to the boiler. When applied to the recoverable energy estimate of $21 \mathrm{MW}$ results in an electricity generation estimate of $2.31 \mathrm{MW}$. (The high hydrogen content of COG results in a higher heat capacity than may be expected for other combustion gases). The carbon savings due to the offsetting of external electricity are estimated based on the emission factor for electricity consumption in 2010 [17], taken as $0.54 \mathrm{~kg} \mathrm{CO} / \mathrm{kWh}$. The operational schedule was assumed to be maintained for 8,580 h/y (assuming $98 \%$ availability). This results in an annual carbon saving of $10,702 \mathrm{t} \mathrm{CO}_{2}$. While, when viewed collectively, this remains a significant carbon savings it does however represent a reduction $1.39 \%$ to the carbon intensity of coke production. 
Using data from Table 1, the overall thermal output of the boiler is calculated at $52 \mathrm{MW}$. Boiler output is estimated at $40 \mathrm{MW}$, confirming the output of the condenser at $12 \mathrm{MW}$. In order to estimate the thermal efficiency, a value for the thermal input to the boiler is necessary. This is estimated using the net calorific value of woodchips $(8.16 \mathrm{Mj} / \mathrm{kg}$ ) and the enthalpies of both the woodchip and air stream (from Table 1 above). This results in a thermal input estimate of $44 \mathrm{MW}$, confirming the overall thermal efficiency of the boiler and condenser at 118\%, as suggested in [6]. This also suggests that the thermal efficiency of boiler itself (i.e. without the condenser) is $91 \%$. Using equation 2 it is estimated that incorporating a condensing boiler will result in a fuel saving of $22 \%$. Given that the estimates in Table 1 include the operation of the condenser, it is assumed to correspond to this saving, representing $78 \%$ of the wood necessary to achieve an output of $52 \mathrm{MW}$ without the use of a condenser. Based on this the operation of the condenser is assumed to avoid an additional 38,381 tonnes of woodchip (and associated 36,059 tonnes of $\mathrm{CO}_{2}$ ) annually. It must be clarified that the operation of a condensing boiler will not result in a decrease in the actual amount of carbon emitted from the facility. Rather the increased thermal efficiency will reduce the carbon intensity per unit of output by allowing for an increased district heating capacity without the need for additional woodchip inputs (which may presumably offset an increased fuel use at domestic level).

\subsection{Lifecycle savings}

Due to the large amount of data involved it is unfeasible to include all the data applied in both calculations. In order to examine the lifecycle implications of installing an ORC system and a condensing boiler boiler, process specific information was incorporated into modules generated by [8]. Two separate modules were calculated for each case study, one in which LGH is recovered and one in which it is not. Keeping all other factors equal, the impact of LGH use is estimated using a lifecycle assessment method. The assessment is carried out using $\mathrm{CML}^{1} 2$ mid-point impact assessment. Within mid-point analysis, inventory results for each environmental impact category are multiplied by a characterisation factor which equates individual emissions to a wider impact category. A simple example is the use of global warming potential to estimate $\mathrm{CO}_{2}$ equivalents. The main stages in the LCA include coal production, transportation and production of coke itself. It was assumed that coking coal was transported from Newcastle, Australia by ship and subsequently by rail. The coal and energy (both electricity and gas) required within the coking process are a fundamental part of LCA. Default direct emission estimates for coke production were augmented with more recent values [18] and flue stream composition data for emission of $\mathrm{CO}_{2}, \mathrm{CH}_{4}$, and $\mathrm{CO}$ [5]. The environmental impact of the production of additional materials within an ORC system was also included based on the heat exchanger area requirement (estimated by the Aspen module). Material compositional information for a suitable turbine and generator system was provided by Siemens (Webster, Pers. Comm.). As can be seen from the results in Table 3, negating the consumption of electricity has a negligible effect on the overall lifecycle impact.

\section{Table 3 about here}

Because of its capacity to reduce the relative feedstock demands associated with district heating the lifecycle effects of LGH recovery are more pronounced. The results below incorporate data from a number of distinct lifecycle stages such as forest nursery, tree cultivation, felling, as well as boiler operation. As can be seen from the Table 4, the operation of a condensing boiler (and associated woodchip savings) reduces the lifecycle impact estimate for most impact categories. The exception being 'abiotic depletion' and 'freshwater aquatic eco-toxicology.' This is not to be unexpected given the increased impacts associated with condensate treatment. Including these categories, a condensing boiler is seen to reduce the lifecycle impacts by an average of $13 \%$.

\section{Table 4 about here}

\footnotetext{
${ }^{1} \mathrm{CML}$ is an (non English) abbreviation for the Institute of Environmental Sciences at the University of Leiden in the Netherlands.
} 
The overall lifecycle impact reduction may seem disappointing considering the associated fuel reduction, however the requirement to maintain flue stream buoyancy after condensation means that the operation of the fan consumes significant amounts of electricity. As electricity is a secondary energy source it will have a greater lifecycle impact (per unit of energy) than woodchips. Indeed the scale of the temperature drop (from $140{ }^{\circ} \mathrm{C}$ to $35^{\circ} \mathrm{C}$ ) means that the net electrical demand at plant (per $\mathrm{MWh}$ ) is increased when this supplementary requirement is included.

\subsection{Techno-economic analysis}

The (installation, engineering, material) costs associated with the installation of the ORC were based on a power law relationship between power generation and reported installation costs for projects of various size. Based on the available thermal energy and the estimated efficiency rating for the ORC in question, the investment cost of a suitable ORC system was estimated to be $2,023 € / \mathrm{kWe}$. Up to a certain output $(1.6 \mathrm{MWe})$, the ratio between equipment and total costs rose linearly with output, beyond which the ratio was seen to level off. On average the equipment and installation/engineering was seen to contribute to $57 \%$ and $43 \%$ of total cots respectively. It was assumed that annual operational and maintenance costs amount to $4 \%$ of total investment costs. Assuming a discount rate of 5\%, the offsetting of purchased electricity the proposed project is seen to break even in 3-6 years, depending on the elements of the calculation. It is reasonable that 5 years represents an upper limit for an acceptable DPP but a period of 3 years would probably be necessary to ensure investment.

\section{Table 5 about here}

The investments cost associated with the condenser will be determined by the choice of material. Equipment costs and installation costs are approximately equal. The main ancillary cost associated reflects the additional energy required to power the flue gas fan necessary to maintain buoyancy after the stark reduction in flue gas temperature following condensation. Additional costs include maintenance and condensate treatment. The revenue is based on fuel savings associated with the increased thermal efficiency. As stated previously, the savings associated with a different chipping regime has been included to test the sensitivity of woodchip price.

\section{Table 6 about here}

As can be seen from the figures above, the increased costs associated with terminal chipping enhances the benefits derived from fuel savings. The results above suggest that the increased cost $(+15 \%)$ of woodchips provided by terminal chipping increase the benefit of the any associated fuel savings, decreasing the DPP by an average of $23 \%$. Based on both analyses it would appear that the recovery of LGH can be economically feasible although this will depend on the targets set by industry.

\section{Discussion}

The results in table 3 show that for the particular LCA weighting system chosen for this evaluation there is a negligible $(<1 \%)$ benefit in the overall environmental impact of the coke production system obtained by installation of an ORC system. The largest improvements are in the reduction to the extent of fossil fuel depletion, while reductions in carcinogen and respiratory organic levels are also achieved, correlating with this reduced fossil fuel combustion. There is also a small reduction in the climate change impact of the overall system achieved by installing the ORC. This reduction must be viewed within the context of coke production itself. The recovery of LGH in the form of electricity does not have the capacity to reduce the demand for coal or gaseous feedstock which, due to the nature of coke production, can not be meaningfully substituted with electricity. Similarly, the combustion of blast furnace gas prevents the need for it to be flared. This would have been the case regardless of whether it was used within the coke oven or not. This case study provides an example of the difficulties in discussing normalised and overall emission savings. While the percentage reduction in fossil fuel use or global warming potential achieved is small, the scale of the industry in the UK is large, magnifying its potential impact. McKenna and Norman [4] estimate an annual coke capacity of 
4.31 Mt for the UK and applying the savings above to this total capacity would result in annual carbon savings of 43,100 tonnes of $\mathrm{CO}_{2}$. In order to place this value in context, the current target is to reduce UK emissions by $34 \%$ of 1990 estimates. In 1990 the iron and steel sector emitted over 24 MT of $\mathrm{CO}_{2}$. A 34\% reduction would represent $8.2 \mathrm{MT}$ of $\mathrm{CO}_{2}$. The overall carbon savings of widespread ORC implementation would contribute to $0.5 \%$ of the required savings. When viewed collectively this represents a significant carbon saving and may provide a more advantageous appraisal of the use of ORC. Corus (who operate the integrated steel facility in question) estimate that $40 \%$ of their electricity demand is currently satisfied by on-site generation such as the use of coke oven and blast furnace gases. It is estimated that this will save approximately 700,000 tonnes $\mathrm{CO}_{2}$. Adopting ORC technology may conceivably increase the current emission savings by $6.2 \%$. This advocacy should however be viewed with a caveat. Modern steel will generally be optimised at the higher temperature range through pinch analysis and a complex network of neat exchangers. For that reason, the recoverable LGH within a steelworks may be of insufficient thermal quality to warrant attention. However the production of coke is a relatively standard process so the estimate for recoverable energy is presented as being feasible. The effective determinant will be whether the plant is an integrated steelworks which produces coke onsite or whether coke is produced offsite and imported directly.

As stated previously the operation of the condensing boiler will significantly reduce the plume temperature and convective flow, requiring an increased electricity demand. More immediately, this will result in the exhaust appearing as a continuous plume of steam which may contradict existent planning or environmental licensing and regulation. This may impact upon plant location and determine additional factors such as stack height. Because of the impact on ambient temperature on plume buoyancy, the legal implication of plume buoyancy may be regionally specific. In some instances this may potentially negate the option of installing a condensing boiler. In examining the lifecycle impact of condensing boiler operation, the impact of an increased electricity demand is seen to reduce the benefits of a significant fuel reduction. This is significant given that electricity is a secondary energy source which incorporates the impacts not just associated with generating the electricity itself but also those impacts embodied in electrical infrastructure and the production of the primary fuels upon which electricity is dependent. By contrast, as the impacts are allocated through the functional life of the plant, reducing the material requirements associated with the condensing boiler has a less discernible effect on the overall impact. By way of comparison, the lifecycle impacts of reducing the plant based electricity demands by 50\% are examined using the same impact categories as in Table 4. A reduction of the electricity demand of the condenser fan by $50 \%$ results in an average lifecycle impact saving of $17 \%$ across all categories. This reinforces the importance of a secondary energy source within LCA. If the additional electricity demands associated with the condenser can be negated by electricity savings elsewhere in the plant, the associated lifecycle impacts are reduced by an average value of $20 \%$. The specific elements of the chosen impact assessment should not be ignored. By way of comparison, the lifecycle inventory data for the woodchip plant was reassessed by the Eco-indicator 99 endpoint assessment method (which attempts to quantify actual human and environmental impacts such as losses to human health and species richness), normalised to west European conditions. Using this method the actions of the condensing boiler were seen to increase the lifecycle impact savings to $21 \%$.

It should be mentioned however that the thermal efficiency gains supplied by the condensing boiler do not provide a realistic appraisal of condensing boiler operations in general. This is due to the high moisture content associated with flue streams from the combustion of raw biomass. The plant under review represents one of the largest biomass fuelled plants in Finland and so may not be representative of condensing boiler applications in general. In other countries, for example, natural gas may represent a more realistic fuel of choice. In order to reassess the potential impact of a different fuel choice, the data in Table 1 was replicated by substituting natural gas. (100\% methane was assumed for simplicity). It is assumed necessary to maintain the same overall output of $52 \mathrm{MW}$. The net calorific value of methane and its stoichiometric combustion pathway (assuming 20\% excess air) are used to estimate the flow rate of fuel and flue gas. The flue gas is assumed to have the same temperature (pre and post condenser) and that the same quotient of latent and sensible heat is recovered. Based on these assumptions the contribution of the condensing boiler is reduced from 12 to 
$7 \mathrm{MW}$. This serves to reduce the fuel savings from $22 \%$ to $14 \%$. While this does reduce the thermal efficacy of the condensing boiler, and cautions against an overly optimistic appraisal it does show that a condensing boiler can result in a fuel savings within different markets.

In undertaking a technoeconomic analysis, the economic value of the electricity displaced by the ORC is significant and could offer potentially attractive payback periods. (Although this will be based on the chosen discount rates, increasing the discount rate to $10 \%$ is seen to increase the DPP of the base case by an average of $14 \%$. Increasing the discount rate to $20 \%$ increases the DPP by approximately $72 \%$ ). However, this is also reliant on the difference between electricity selling and purchase prices. If the site owner/operator were to sell the electricity the revenue from this would be much lower than the cost savings incurred by their not having to purchase the electricity from an external supplier. In other words, reducing the demand for external electricity will result in a much shorter payback period than can be expected if electricity or carbon offsets are sold on the market. This is likely to prove significant for other LGH recovery systems where the capacity to directly use recovered energy (in this case electricity) may not be available. Despite the benefits of adopting "over the fence" benefits, the economic reality of these scenarios in the current market may act as a barrier to implementation. By contrast the provision of district heat through the use of condenser presents a different set of challenges. As opposed to the operation of the coke oven, heat itself is the main process output. This means that while there may be a consistent demand for the heat, the peak demand for will need to be satisfied. The output of the boiler (without the condenser) represents full fuel feed so it could be argued that the additional output of the condenser may (wholly or partially) satisfy peak demand. In that regard value of the additional heat may represent more rational revenue for the condenser than a reduction in woodchip demand. Assuming an average price of $45 € / \mathrm{MWh}$ [19] for Finnish district heat and an operational period of 7,000 hours pa, this additional output of $12 \mathrm{MW}$ is seen to reduce the DPP to 1.4 and 0.54 years for stainless and carbon steel respectively.

Perhaps the most interesting point of debate is the implications for determining both assessment criteria and targets for the recovery of LGH. Both case studies represent fundamentally different systems with which to recover heat in different forms. This also reaffirms that each case study for the recovery of LGH must be viewed within its own context. While the electricity generated using the ORC does not demonstrate a significant reduction per functional unit it is important to remember the ORC cannot change the feedstock demand of an inherently carbon intensive process. However the overall carbon savings may be seen as being significant. By contrast the operation of the condensing boiler will not result in a reduction in the actual emissions and requires extra demand (which again questions the wider applicability of the assessment) to capitalise on this increase in thermal efficiency. The question of whether overall or normalised reduction targets should be adopted require more input than be afforded by two case studies. However theses studies raise two important points. Firstly, the fundamental variability in LGH supply and recovery will frustrate attempts to standardise any assessment criteria and targets. Secondly it is likely that lifecycle resource demands will reduce the impact of LGH recovery and has implications for any proposed targets.

\section{$5 \quad$ Conclusion}

The economic and environmental analyses provide disparate appraisals of the impact of the ORC to recover LGH from flue gas emitted during coke production. The process under review is a carbon intensive process, particularly when blast furnace gas is used. Despite this, the potential savings due to on-site electricity generation suggest a DPP of less than 4 years. This is reliant on the difference between electricity selling and purchase prices. The operation of a condensing boiler has been shown to increase plant thermal efficiency from $91 \%$ to $118 \%$. This increases the thermal output to $52 \mathrm{MW}$. However the use of the condensing boiler necessitates additional electricity consumption which reduces the lifecycle benefits of the condenser. In economic terms, the DPP associated with the condenser varies significantly depending on material type, discount rate and chipping regime. While many estimates fall within a timeframe of 5 years, it appears that carbon steel represents a more feasible material choice, particularly if terminal chipping is used. Overall the results demonstrate that LGH is a variable resource whose utility and capacity to reduce emission and improve process 
efficiency will depend not just on the process itself but on the form in which it is recovered as well as the apparent demand. This variability means that any proposed criteria or targets for LGH recovery will have to be sufficiently tailored to be widely applicable but also highlight the advantages which may not be immediately apparent (such as in the case of the coke oven). Overall it should be reaffirmed that "win-win" scenarios which perform favourably from both an environmental and economic perspective are possible through the recovery of LGH.

\section{References}

[1] T.C. Hung, Y.T. Shai, S.K. Wang, A review of Organic Rankine Cycles for the recovery of lowgrade waste heat. Energy. 22 (1997) 661-667.

[2] A. Lakew, O. Boland, Working fluids for low-temperature heat source. Applied Thermal Engineering. 30(2010) 1262-1268.

[3] B.T. Liu, K. Chien, C. Wang, Effect of working fluids on organic Rankine cycle for waste heat recovery. Energy. 29 (2004) 1207-1217.

[4] R.C. McKenna, J.B. Norman, Spatial modelling of industrial heat loads and recovery potentials in the UK. Energy Policy. 38(2010) 5878-5891.

[5] University of Newcastle, National sources of low grade heat available from the process industry EPSRC: Thermal Management of Industrial Processes. (2010).

[6] Q. Chen, K. Finney, H. Li, X. Zhang, J. Zhou, V. Sharifi, J. Swithenbank, Condensing boiler applications in the process industry. Energy (2010) Article in Press.

[7] IPCC. Gomez at al., Stationary combustion, In: H. S.Eggleston, L.Buendia, K.Miwa, T.Ngara, and K.Tanabe (Eds). Guidelines for National Greenhouse Gas Inventories, prepared by the National Greenhouse Gas Inventories Programme, IGES, Japan, (2006) pp.2.1-2.47.

[8] Pre Consultants, Simapro lifecycle software [v7.2], (2007). Amersfoort, the Netherlands.

[9] M.L. Juntunen, Use of pesticides in Finnish forest nurseries in 1996. Silva Fennica 35 (2001) 147157.

[10] S. Berg, T. Karjalainen, A comparison of Greenhouse gas emissions from forest operations in Finland and Sweden. Foresty. 76 (2003) 271-284.

[11] S. Berg, E.L. Lindholm, Energy use and environmental impacts of forest operations in Sweden. 13(2005) 33-42.

[12] E.L. Lindholm, S. Berg, P.A. Hansson, Energy efficiency and the environmental impact of harvesting stumps and logging residues. Eur J Forest Res. 129 (2010)1223-1235.

[13]Y. Aldentun, Lifecycle inventory of forest seedling production: from seed to regeneration site. Journal of Cleaner Production. 10 (2002) 47-54.

[14] M. Wihersaari, Greenhouse gas emissions from final harvest fuel chip production in Finland.

Biomass and Bioenergy. 28 (2005) 435-443.

[15] DECC, Energy price statistics. Department of energy and climate change.(2010). London.

[16] J. Laitila, Cost structure of supply chains in Finland. (2005).Finnish Forest Research Institute.

NorthernWood Heat Symposium.

[17] AEA, Guidelines to Defra GHG Conversion Factors for Company Reporting. (2010). London.

[18] USEPA, Emission Factor Documentation for AP-42 Section 12.2. Coke Production: Final Report. United States Environmental Protection Agency. (2008). North Carolina.

[19] J. Kostama, District Heat Price Formation Perspectives in Finland. Finnish Energy Industries. (2011) 


\section{Figure Captions}

Figure 1: simple (Organic) Rankine Cycle taken from Hung et al., [1].

Figure 2: Woodchip boiler process diagram, taken from [6].

\section{Table Captions}

Table 1: Process stream parameters. Taken from [6].

Table 2: ORC operational parameters in $\mathrm{kj} / \mathrm{h}$.

Table 3: Lifecycle impact of producing $1 \mathrm{~kg}$ of coke, including LGH recovery.

Table 4: Lifecycle impact of producing $1 \mathrm{MWh}$ of district heat, including LGH recovery.

Table 5: DPP and NPV for ORC investment based on CCL and Tax. 5\% discount rate.

Table 6 Impact of chipping regime on DPP in years. Off-site chipping estimates taken from [3]. 